\title{
Quantitative Detection of Chromium Pollution in Biochar Based on Matrix Effect Classification Regression Model
}

\author{
Mei Guo ${ }^{1,2}$, Rongguang Zhu ${ }^{1}$, Lixin Zhang ${ }^{1}$, Ruoyu Zhang ${ }^{3}$, Guangqun Huang ${ }^{4}$ and Hongwei Duan ${ }^{1,2,4, *}$ \\ 1 College of Mechanical and Electrical Engineering, Shihezi University, Shihezi 832003, China; \\ guomei901116@163.com (M.G.); rgzh_jd@163.com (R.Z.);Zhlx2001730@126.com (L.Z.) \\ 2 College of Agricultural Engineering, Jiangsu University, Zhenjiang 212013, China \\ 3 Key Laboratory of Northwest Agricultural Equipment, Ministry of Agriculture and Rural Affairs, \\ Shihezi 832003, China; ry248@163.com \\ 4 Laboratory of Biomass and Bioprocessing Engineering, College of Engineering, China Agricultural University, \\ Beijing 100083, China; huangguangqun@126.com \\ * Correspondence: dhwsg123@cau.edu.cn; Tel.: +86-18-260-625-298
}

Citation: Guo, M.; Zhu, R.;

Zhang, L.; Zhang, R.; Huang, G.;

Duan, H. Quantitative Detection of

Chromium Pollution in Biochar Based on Matrix Effect Classification

Regression Model. Molecules 2021, 26, 2069. https://doi.org/10.3390/

molecules26072069

Academic Editor: Tomasz Tuzimski

Received: 15 March 2021

Accepted: 1 April 2021

Published: 3 April 2021

Publisher's Note: MDPI stays neutral with regard to jurisdictional claims in published maps and institutional affiliations.

Copyright: (c) 2021 by the authors. Licensee MDPI, Basel, Switzerland. This article is an open access article distributed under the terms and conditions of the Creative Commons Attribution (CC BY) license (https:// creativecommons.org/licenses/by/ $4.0 /)$.
Abstract: Returning biochar to farmland has become one of the nationally promoted technologies for soil remediation and improvement in China. Rapid detection of heavy metals in biochar derived from varied materials can provide a guarantee for contaminated soil, avoiding secondary pollution. This work aims first to apply laser-induced breakdown spectroscopy (LIBS) for the quantitative detection of $\mathrm{Cr}$ in biochar. Learning from the principles of traditional matrix effect correction methods, calibration samples were divided into 1-3 classifications by an unsupervised hierarchical clustering method based on the main elemental LIBS data in biochar. The prediction samples were then divided into diverse classifications of calibration samples by a supervised K-nearest neighbor $(\mathrm{KNN})$ algorithm. By comparing the effects of multiple partial least squares regression (PLSR) models, the results show that larger numbered classifications have a lower averaged relative standard deviations of cross-validation (ARSDCV) value, signifying a better calibration performance. Therefore, the 3 classification regression model was employed in this study, which had a better prediction performance with a lower averaged relative standard deviations of prediction (ARSDP) value of $8.13 \%$, in comparison with our previous research and related literature results. The LIBS technology combined with matrix effect classification regression model can weaken the influence of the complex matrix effect of biochar and achieve accurate quantification of contaminated metal $\mathrm{Cr}$ in biochar.

Keywords: biochar; matrix effect; unsupervised/supervised classification; classification regression model; LIBS

\section{Introduction}

Returning biochar to farmland has become a research hotspot in China, since it can improve the quality of cultivated land [1]. Because of the enrichment effect of heavy metals during crop growth and crop-straw pyrolysis, the heavy metals in crop straw-based biochar may exceed the carrying capacity of farmland soil, resulting in secondary pollution. Therefore, the International Biochar Initiative (IBI) specifically highlights the importance of the analytical characteristics and producer's certification of biochar as a soil remediation agent [2]. However, there are only a small number of reports about the production quality standards of biochar, and it is necessary to quantitatively and qualitatively analyze heavy metals in biochar with reference to soil pollution risk control standards.

Several rapid detection methods, such as biochemical sensors [3,4], test paper detection [5,6], the indicator biological method [7], enzyme-linked immunosorbent assay [8,9] and spectral analysis [10-12], have been widely used for metal detection in the fields of industrial analysis [13,14], biomedical engineering [15], food safety [16-18] and environmental ecological pollution assessment [19]. This can not only reduce the limit of detection 
(LOD), but can also improve the sensitivity and detection efficiency. In comparison with the other methods, spectral analysis has the advantages of multi-elemental high-throughput rapid detection when it is integrated with multiple chemo-metrics or even artificial intelligence algorithms. However, it is urgent to develop a simpler spectral analysis instrument with little sample pretreatment to avoid the complex sample pretreatment of traditional analysis instruments [20-22].

Laser-induced breakdown spectroscopy (LIBS) is a new elemental analytical technology that uses the atomic or ionic spectra emitted when laser ablates the sample surface in the focal plane. However, it still faces challenges in the accurate quantitative analysis of complex matrixes such as those in agricultural and food samples. The matrix effect mainly affects the plasma parameters (temperature, electron number density, etc.) and the ablation amount of the samples. The matrix characteristics of complex samples have a great influence on the total ablation amount of laser-excited samples. The larger the concentration difference between the matrix (main elements) and the analytical element, the more serious the interference effects will be. Generally, the standard addition method [23], the matrix matching method [24] and the pre-separation/enrichment method [25] are used for matrix effect correction. The standard addition method is mainly implemented to add pure substances with a certain quality as internal standards to the mixture of analyzed samples, and calculate the content of the tested components according to the mass ratio, the spectral peak areas ratio and relative correction factors. However, the matrix matching method has similar interference to the analysis elements because of the similar principal components, and the interference of matrix or principal components can be deducted by matching method. It can be seen that the main components in complex matrix have a great influence on the spectrum of LIBS of the analytical element, and the matrix effect of the analytical element has a similar regularity because of the similar concentration and existing form of the main components.

To remove the cumbersome process of traditional matrix matching or standard adding, a more efficient method of matrix effect classification is proposed. It uses an unsupervised hierarchical clustering method [26] to classify calibration samples based on the main elemental LIBS data, and develops multiple regression models for different matrix classifications. Then, the prediction samples are divided into diverse classifications of calibration samples by supervised KNN algorithm [27], and a quantitative prediction is made based on the best matrix classification regression model.

\section{Results and Discussion}

\subsection{Matrix Elemental Analysis}

Figure 1 shows that the carbonized straw fiber still maintains the graphite flake morphology, indicating the existence of a large amount of carbon. The statistical analysis of energy dispersive spectrometer (EDS) shows that the main elements in biochar are carbon $(\mathrm{C})$, oxygen $(\mathrm{O})$ and potassium $(\mathrm{K})$, and their contents are about $59.36 \%, 17.49 \%$ and $9.99 \%$, respectively. These results show high consistency with the relevant literature [28,29]. However, the $\mathrm{Cr}$ content is difficult to semi-quantitatively characterize and analyze, since its trace concentration exceeds the detection limit of EDS. Therefore, the matrix effect of the three elements is studied and applied for the classification of biochar samples.

\subsection{Spectral Classification of Matrix Effect}

The spectra of $\mathrm{C}, \mathrm{O}, \mathrm{K}$ and $\mathrm{Cr}$ in three biochar samples derived from rice husk (3\#), rice straw (54\#) and corn stalk (18\#) were in the range of $192-846 \mathrm{~nm}$, as presented in Figure 2. Two biochar samples (3\#, 54\#) should have a similar analytical spectral intensity of $\mathrm{Cr}$ on account of their similar concentration. In addition, the analytical spectral intensity of sample 18\# should be higher than that of biochar samples (3\#,54\#) because of its higher $\mathrm{Cr}$ content. Conversely, this is not the case. Furthermore, there was an obvious difference in the spectral intensities of main elements (C193.03 nm, C247.84 nm, O777.1 nm, O777.29 nm, O844.64 nm, K $766.29 \mathrm{~nm}$ and K $769.79 \mathrm{~nm}$ ) in these three samples. The reason for this may 
be that the analytical spectra of $\mathrm{Cr}$ were interfered with by the matrix effect of the main elements of $\mathrm{C}, \mathrm{O}$ and $\mathrm{K}$ in biochar.

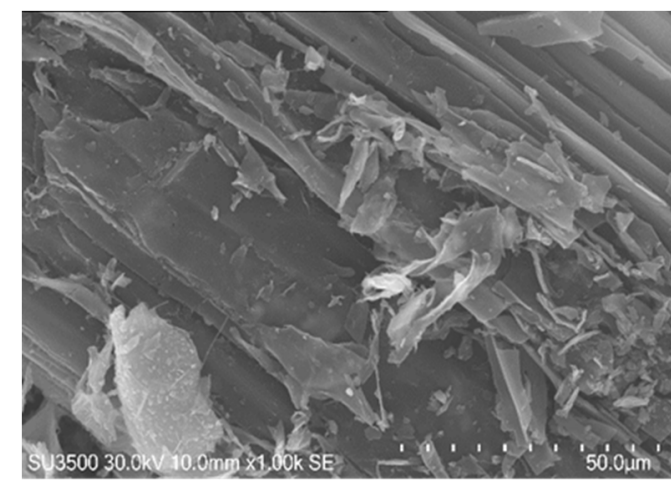

(a) SEM morphology analysis

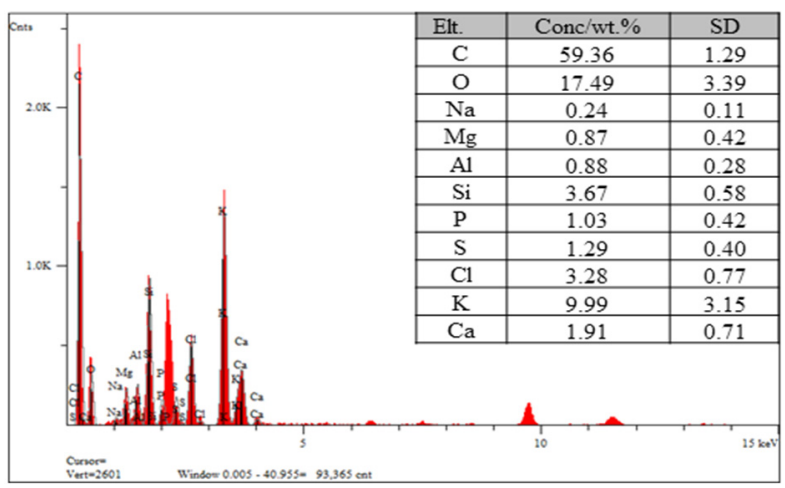

(b) EDS Semi-quantitative analysis of elements

Figure 1. SEM (a) and EDS (b) analysis of biochar.

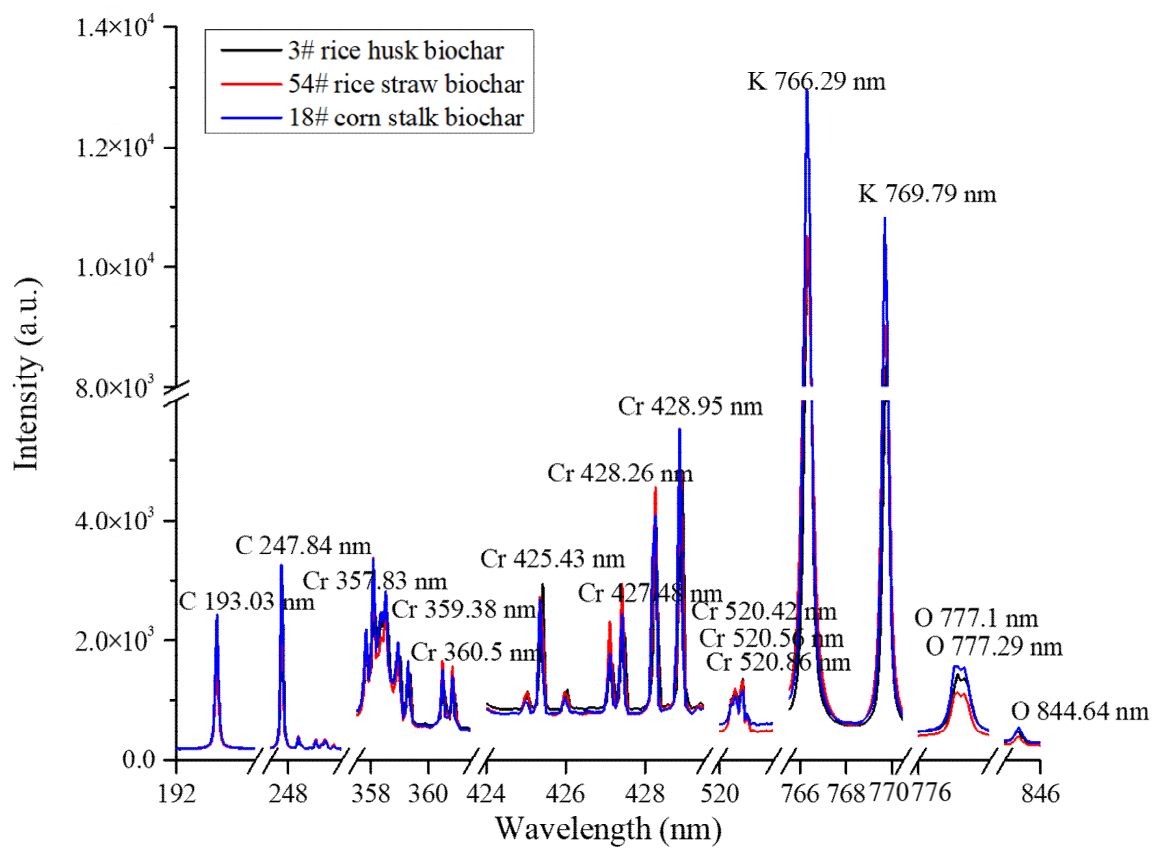

Figure 2. LIBS spectra of biochar. 
However, the main elements suffered from few matrix effects due to their insignificant relative deviations of concentration; it was attempted to use their LIBS spectra to divide the biochar samples into diverse classifications. As for the $\mathrm{K}$ element, its analytical spectra of K $766.29 \mathrm{~nm}$ and K $769.79 \mathrm{~nm}$ were easily affected by the self-absorption effect [30]. Therefore, spectra of C193.03 nm, C247.84 nm, O777.1 nm, O777.29 nm and O844.64 $\mathrm{nm}$ were employed for classifying biochar samples, since these were the two elements with the highest concentration. Here, the calibration samples were divided into 1-3 classifications using hierarchical clustering method, and the supervised classification of prediction samples was carried out by KNN algorithm based on the classified calibration samples. The results of 2 and 3 classifications are shown in Figure 3.

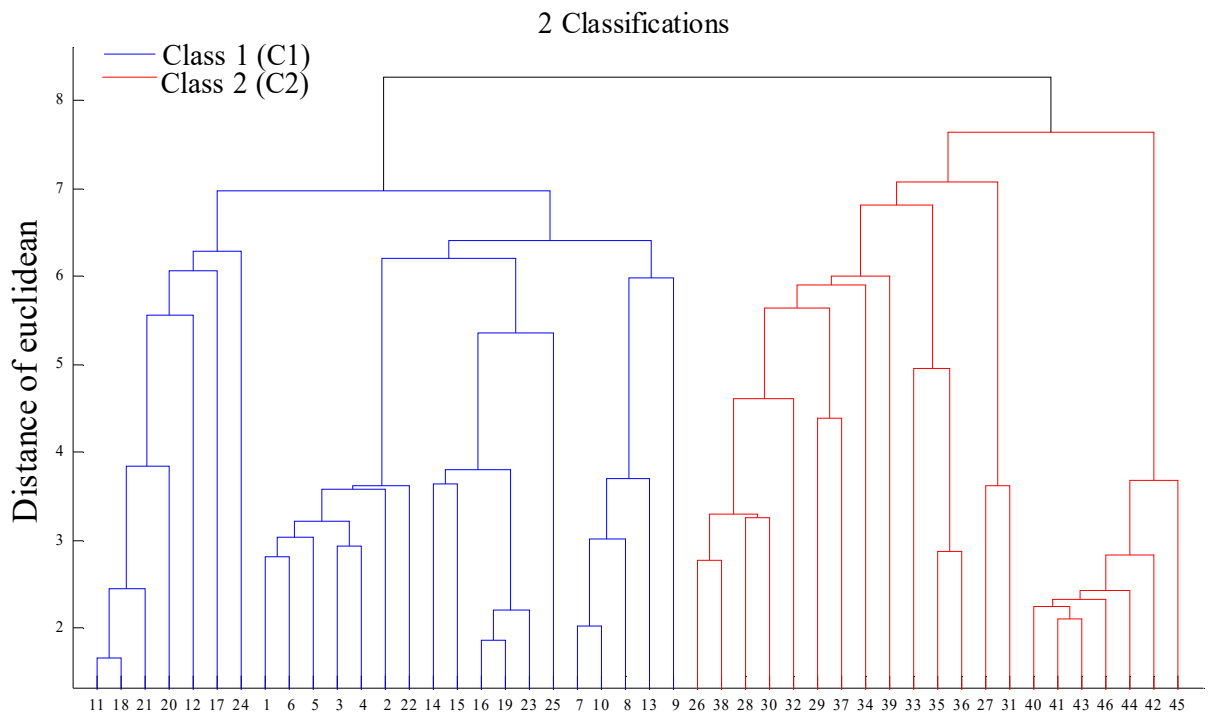

(a) 2 classifications of calibration samples

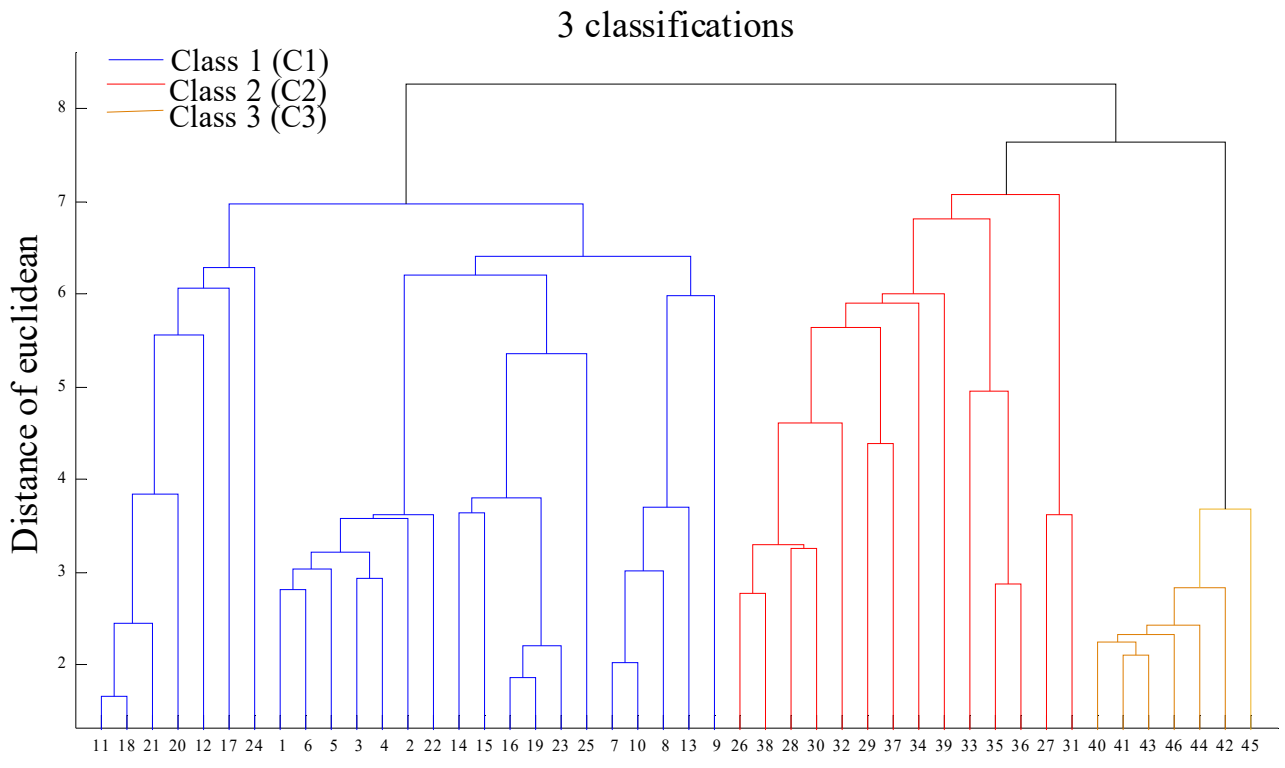

(b) 3 classifications of calibration samples

Figure 3. Unsupervised 2 classifications (a) and 3 classifications (b) hierarchy diagram of calibration samples. 
As for the 2 classifications of the biochar matrix, it can be observed from Figure 3 that samples 1-25 and 26-46 of the calibration set in the 1 classification were divided unsupervised into the first (C1) and second (C2) classification, respectively, while samples 47-53 and 54-60 of the prediction set in the 1 classification were divided supervised into $C 1$ and C2, respectively, as shown in Table 1 . As for the 3 classifications of the biochar matrix, similar results were obtained from Figure 3b, whereby samples 1-25, 26-39 and 40-46 were divided unsupervised into the first (c1), second (c2) and third (c3) classification, while 47-53, 54-58 and 59-60 samples were divided supervised into c1, c2 and c3, respectively. Moreover, the two supervised models of KNN both have a robust performance due to their classification accuracies of cross-validation (CACV), which are higher than $90 \%$. This indicates that the unsupervised 2 and 3 classification of calibration samples can be used for supervised classification of prediction samples Table 1.

Table 1. Classification results of biochar samples.

\begin{tabular}{|c|c|c|}
\hline Main Matrix & 2 classifications & 3 Classifications \\
\hline $\mathrm{C}+\mathrm{O}(76.85 \%)$ & $\begin{array}{c}\text { C1: } 1-25 \text { (calibration), } 47-53 \\
\text { (prediction) } \\
\text { C2: } 26-46 \text { (calibration), } \\
54-60 \text { (prediction) }\end{array}$ & $\begin{array}{l}\text { c1: } 1-25 \text { (calibration), } 47-53 \\
\text { (prediction) } \\
\text { c2: } 26-39 \text { (calibration), 54-58 } \\
\quad \text { (prediction) } \\
\text { c3: } 40-46 \text { (calibration), 59-60 } \\
\quad \text { (prediction) }\end{array}$ \\
\hline
\end{tabular}

\subsection{Classification Regression Model}

The peak broadening wavebands of Cr $357.83 \mathrm{~nm}, \mathrm{Cr} 359.38 \mathrm{~nm}, \mathrm{Cr} 360.5 \mathrm{~nm}$, Cr 425.43 nm, Cr 427.48 nm, Cr 428.26 nm, Cr 428.95 nm, Cr 520.42 nm, Cr 520.56 nm and $\mathrm{Cr} 520.86 \mathrm{~nm}$ as shown in Figure 2 were employed to develop multivariate classification regression model of PLSR. The results of classification regression models in 1-3 classifications are shown in Table 2. Prior to developing calibration model, the LIBS data of $\mathrm{Cr}$ were preprocessed using the same algorithm in order to evaluate the model effect fairly.

Table 2. Results of classification regression model.

\begin{tabular}{ccccc}
\hline Classifications & Classification & RMSECV (mg/kg) & RSDCV (\%) & ARSDCV (\%) \\
\hline 1 & None & 2.38 & $18.53 \%$ & $18.53 \%$ \\
\hline \multirow{2}{*}{2} & C1 & 1.99 & $12.70 \%$ & \multirow{2}{*}{$18.11 \%$} \\
& C2 & 2.23 & $23.51 \%$ & \\
\multirow{2}{*}{3} & c1 & 1.99 & $12.70 \%$ & $12.32 \%$ \\
& c2 & 1.38 & $11.02 \%$ & \\
\hline
\end{tabular}

The 1 classification regression model of PLSR was initially developed using the calibration set of 1-46 samples, resulting in the RSDCV value of $18.53 \%$, while the 2 classification regression models were developed using two calibration sets of samples 1-25 and 26-46, yielding the RSDCV values of $12.70 \%$ and $23.51 \%$. The results show that the 1 classification regression model effect is more robust than that of the second model in the 2 classification regression model, but is inferior to that of the first model. This indicates that the concentration and occurrence form of $\mathrm{C}$ and $\mathrm{O}$ in samples 1-25 are more similar, and the matrix effect is weak, which may not need to be subdivided again; meanwhile, some samples with a greater degree of matrix effect still exist in samples 26-46, which may need a second division. It was verified that samples 1-25 were divided into both the first classification in the 2- and 3 classifications, and the second classification samples in the 2 classifications were subdivided into the second and third classification samples in the 3 classifications, as shown in Table 1. The subdivided samples were used to develop PLSR models, yielding a lower RSDCV values of $11.02 \%$ and $13.24 \%$ than that of the second model in the 
2 classifications. The results show that 3 classifications can further weaken the matrix effect of 2 classifications. The averaged relative standard deviations of cross-validation set (ARSDCV) of classification regression models in 1-3 classifications were 18.53\%, 18.11\% and $12.32 \%$, respectively. This indicates that a classifications with a larger number have a better calibration performance, and the 3 classification regression model has the best modeling effect. This verifies that matrix effect of samples with similar concentrations and occurrence forms of main elements may be consistent, which leads to regular changes in the analytical spectra of $\mathrm{Cr}$, and thus the matrix noise can be removed by normal preprocessing algorithms and the model performance can be improved. Thus, the 3 classification regression model of matrix effect classification partial least squares (MEC-PLS) was employed to quantitatively predict $\mathrm{Cr}$ content in biochar, resulting in the averaged relative standard deviations of prediction set (ARSDP) value of $8.13 \%$ as shown in Table 3 .

Table 3. Cr detection in biochar and soil in related literature.

\begin{tabular}{cccccc}
\hline Particle & Element & Range $(\mathbf{m g} / \mathbf{k g})$ & RSDP/ARSDP (\%) & Remarks & Ref. \\
\hline Biochar & $\mathrm{Cr}$ & $2.92-25.38$ & $8.13 \%$ & MEC-PLS $^{1}$ & In this work \\
Soil & $\mathrm{Cr}$ & $48-410$ & 23.019 & MIPW-PLS & Fu et al. 2017 [31] \\
Soil & $\mathrm{Cr}$ & $48-410$ & 17.673 & FSC-MIPW-PLS & Duan et al. 2018 [32] $^{3}$ \\
Soil & $\mathrm{Cr}$ & $18.29-164.06$ & 11.460 & Lasso $^{2}$ & Wang et al. 2018 [33] \\
Biochar & $\mathrm{Cr}$ & $5.05-19.15$ & $17.41 \%$ & PLS & Duan et al. 2019 [34] \\
\hline
\end{tabular}

${ }^{1}$ MEC-PLS: matrix effect classification partial least squares; ${ }^{2}$ MIPW-PLS: modified iterative predictor weighting-partial least squares;

${ }^{3}$ FSC-MIPW-PLS: full spectrum correction and modified iterative predictor weighting-partial least squares. ${ }^{4}$ Lasso: least absolute shrinkage and selection operator.

The performance in this work was superior to that of Fu et al. [31] and Duan et al. [32], and was comparable to that of Wang et al. [33]. This may be explained on the basis that, on the one hand, sensitive variables were all extracted from the full spectrum by the modified iterative predictor weighting (MIPW), full spectrum correction and modified iterative predictor weighting (FSC-MIPW) and Lasso algorithms in the related literature. However, the emission lines of multiple elements were all employed to develop the calibration models for predicting the $\mathrm{Cr}$ content, but the sensitive variables with large weight coefficients varied in these three reports. This means that the prediction ability of these models may be poor since their sensitive variables may not be suitable for soils in different habitats. One the other hand, the related literature should have a more robust performance than this work since a larger concentration of $\mathrm{Cr}$ signifies a stronger signal and a larger signal-to-noise ratio. However, the complex matrix effect present in these samples cannot be reduced by these sensitive variable extraction algorithms, resulting in the high degree of noise in the LIBS analytical spectra of Cr. Moreover, the ARSDP value of the developed 3 classification regression model decreased by $9.28 \%$ in comparison with our previous work [34] at similar concentrations. The reason for this may be that the unsupervised/supervised classification methods can successfully divide the tested samples into different classifications, which can obviously weaken the influence of matrix effect on the analytical spectra of $\mathrm{Cr}$. In addition, the predicted values of $\mathrm{Cr}$ content in biochar were all below the risk value of $150 \mathrm{mg} / \mathrm{kg}$ according to "the soil environmental quality control standard for agricultural land soil pollution risk (Trial)" (GB15618-2018). The performance of the 3 classification regression model in terms of measured vs. predicted values of $\mathrm{Cr}$ in biochar are plotted in Figure 4. 


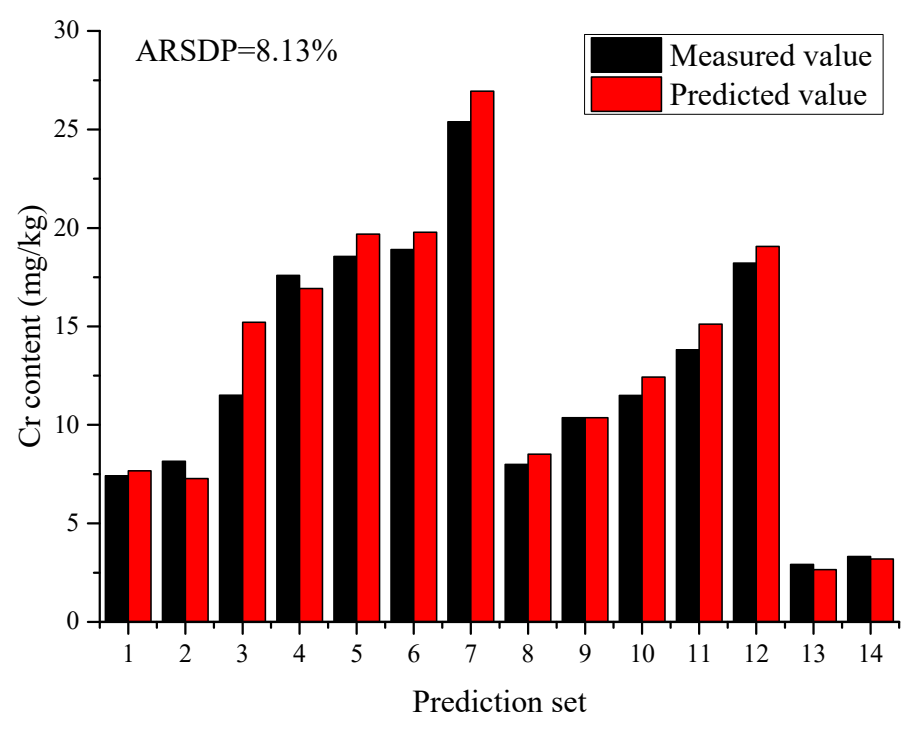

Figure 4. Prediction results of the 3 classification regression model.

\section{Experimental Design and Methods}

\subsection{LIBS Device}

The Benchtop LIBS (TSI, Minnesota, USA) apparatus is equipped with a Q-switched $\mathrm{Nd}$ :YAG laser emitting at $1064 \mathrm{~nm}$ and operating at a maximum frequency and energy of $2 \mathrm{~Hz}$ and $100 \mathrm{~mJ}$, with a pulse width of $10 \mathrm{~ns}$. The detector is a seven-channel spectrometer charge coupled device (CCD) array, with a wavelength range of 187.78-982.29 $\mathrm{nm}$ and a spectral resolution of $\lambda / \Delta \lambda=12,291$.

To reduce the influence of laser pulse energy fluctuation on spectral intensity, the laser energy and spot size is set to $30 \mathrm{~mJ}$ and $200 \mu \mathrm{m}$, the number of single-point laser repeated ablations is 3 . To avoid bremsstrahlung, the delay time of detector relative to laser pulse is set to $0.7 \mu \mathrm{s}$. After spectral collection of multiple spots on the sample surface, the averaged spectrum was taken as the final spectrum of each sample.

\subsection{Sample Preparation}

Sixty biochar samples derived from varied materials of rice husk, rice straw and corn straw were collected from Nanjing Zhironglian Technology Co., Ltd. (Nanjing, China). These samples were crushed using a pulverizer (WKF-130 type, Weifang, China) and screened with a $75 \mu \mathrm{m}$ sieve, the resulting samples were placed in valve bags for use. Prior to spectral acquisition, each crushed sample was fixed on an aluminum substrate using the double-sided tape tableting method [35] to avoid the problems of poor molding effect and laser ablation splash caused by traditional tableting method.

Semi-quantitative analysis was primarily implemented to determine the main elements in biochar by using the scanning technology of EDS (SDD3310, IXRF Systems, Austin, TX, USA) attached to SEM (SU3500, Hitachi, City Tokyo, Japan) [36]. Each sample was determined three times. Furthermore, the $\mathrm{Cr}$ content in samples was determined by ICP-MS (PE NexION 300, Waltham, MA, USA) [37], as shown in Table 4. It was observed that the Cr content in derivations of rice straw and rice husk was similar, but it was lower than that in corn straw-based biochar. This may be attributed to the fact that corn straw has a better enrichment power of $\mathrm{Cr}$ than that of rice straw and rice husk. According to the "soil environmental quality-agricultural land soil pollution risk control standard (trial)" (GB15618-2018) in China, the $\mathrm{Cr}$ content in biochar derived from the three materials is lower than the farmland soil pollution risk control value of $150 \mathrm{mg} / \mathrm{kg}$. 
Table 4. Statistical results of $\mathrm{Cr}(\mathrm{mg} / \mathrm{kg})$ content.

\begin{tabular}{|c|c|c|c|c|c|c|c|}
\hline $\begin{array}{c}\text { Derivation } \\
(\# 1 \sim \# 15)\end{array}$ & Content & $\begin{array}{c}\text { Derivation } \\
(\# 16 \sim \# 30)\end{array}$ & Content & $\begin{array}{c}\text { Derivation } \\
(\# 31 \sim \# 45)\end{array}$ & Content & $\begin{array}{c}\text { Derivation } \\
(\# 46 \sim \# 60)\end{array}$ & Content \\
\hline rice husk & 7.37 & corn stalk & 18.21 & rice straw & 10.67 & rice husk & 4.5 \\
\hline rice husk & 7.47 & corn stalk & 18.63 & rice straw & 11.47 & rice husk & 7.42 \\
\hline rice husk & 7.83 & corn stalk & 18.88 & rice husk & 11.73 & rice husk & 8.15 \\
\hline rice husk & 8.11 & corn stalk & 18.9 & rice straw & 12.81 & rice husk & 11.51 \\
\hline rice husk & 8.22 & corn stalk & 18.98 & rice husk & 13.75 & corn stalk & 17.59 \\
\hline rice husk & 8.53 & corn stalk & 19.15 & rice husk & 15.15 & corn stalk & 18.55 \\
\hline rice husk & 10.59 & rice husk & 19.56 & rice straw & 16.47 & corn stalk & 18.91 \\
\hline rice husk & 11.54 & corn stalk & 26.15 & corn stalk & 17.08 & corn stalk & 25.39 \\
\hline rice husk & 12.11 & corn stalk & 26.34 & corn stalk & 20.15 & rice straw & 7.99 \\
\hline rice husk & 12.52 & corn stalk & 28.51 & rice straw & 2.79 & rice straw & 10.36 \\
\hline corn stalk & 15.27 & rice straw & 7.9 & rice straw & 2.9 & rice straw & 11.5 \\
\hline corn stalk & 15.61 & rice straw & 8.37 & rice straw & 3.04 & rice straw & 13.81 \\
\hline rice husk & 17.28 & rice straw & 9.32 & rice straw & 3.28 & corn stalk & 18.22 \\
\hline corn stalk & 17.94 & rice straw & 9.9 & rice straw & 3.3 & rice straw & 2.92 \\
\hline corn stalk & 18.03 & rice straw & 10.6 & rice straw & 3.98 & rice straw & 3.32 \\
\hline
\end{tabular}

\subsection{Matrix Effect Classification Regression Modeling and Evaluation Criteria}

Matrix effects can be divided into physical effects, chemical effects and absorption enhancement effects between elements $[38,39]$. Physical effects are mainly caused by particle size and inhomogeneity, which can be weaken by crushing and tableting. Chemical effects are mainly due to the crystal structure of the analytical element, which is weak for LIBS technology, since the high-energy laser could instantly transform the crystalline state into a high-temperature plasma state. However, the absorption enhancement effects between elements refer to the phenomenon whereby the analytical elemental spectrum depends not only on its own concentration, but also on the properties and concentration of main elements in samples. Fortunately, it can be understood from principles of matrix matching method and the standard addition method that the main elements in a complex matrix have a great influence on the analytical elemental LIBS spectra. Moreover, a more similar concentration and occurrence form of the main elements may signify a more similar matrix effect on the analytical element. Therefore, a new matrix effect classification regression model is proposed in this study. The main elements of collected biochar samples were firstly determined by X-ray energy dispersive spectrometer, the LIBS data of which were employed to classify the calibration samples using the unsupervised hierarchical clustering method [26]. Similarly, the prediction samples were divided into various classifications of calibration samples on the basis of a supervised KNN algorithm [27]. Multiple classification regression models of PLSR [40] were developed and compared, of which the model with the best calibration performance was employed for quantitative prediction.

The performance of PLSR models was evaluated by the root mean square errors of cross-validation (RMSECV) and prediction (RMSEP) sets, relative standard deviations of cross-validation (RSDCV) and prediction (RSDP) sets [40]. The formulas of RMSECV, RMSEP, RSDCV and RSDP are, respectively:

$$
\begin{gathered}
\text { RMSECV }=\sqrt{\frac{\sum_{1}^{m}\left(y_{i, a c t u a l}-y_{i, \text { predicted }}\right)^{2}}{m-1}} \\
\operatorname{RMSEP}=\sqrt{\frac{\sum_{1}^{n}\left(y_{i, a c t u a l}-y_{i, \text { rredicted }}\right)^{2}}{n-1}} \\
\operatorname{RSDCV}(\%)=\frac{R M S E C V}{\bar{y}}=\frac{\sqrt{\frac{\sum_{1}^{n}\left(y_{i, a c t u a l}-y_{i, p r e d i c t e d}\right)^{2}}{n-1}}}{\bar{y}} \times 100 \%
\end{gathered}
$$




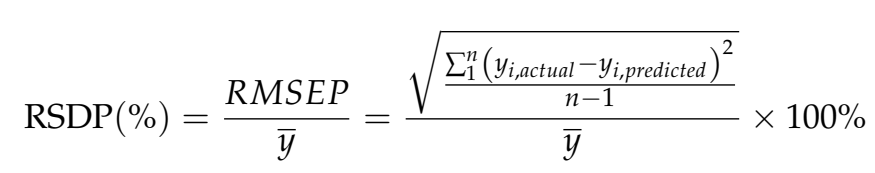

where $m$ and $n$ are the sample numbers of calibration and prediction sets, respectively; and are the measured and predicted values, respectively; and is the averaged value of prediction set. A lower value of RSDCV (or a lower value of RMSECV) signifies a better modeling effect, while a lower value of RSDP (or a lower value of RMSEP) signifies a better prediction accuracy [40].

\section{Conclusions}

In this study, we investigated the feasibility of applying LIBS technology for the quantitative analysis of heavy metal $\mathrm{Cr}$ in biochar. To reduce the influence of complex matrix effects, calibration samples of biochar were divided unsupervised into 1-3 classifications using the main elemental LIBS data by hierarchical classification method. The prediction samples were divided supervised into diverse classifications of calibration samples by the KNN algorithm. In comparison with the other two classification regression models, the 3 classification regression model showed a more robust performance in modeling, which was finally employed for quantitative analysis of prediction set. Furthermore, the developed MEC-PLS models had a better prediction performance, with a lower ARSDP value of $8.13 \%$, in comparison with our previous research and related literature results. The predicted values of $\mathrm{Cr}$ content in biochar were all below the risk value of $150 \mathrm{mg} / \mathrm{kg}$ (GB15618-2018). The results imply that the element of $\mathrm{Cr}$ in the produced biochar are within the carrying capacity of farmland soil, which will not trigger a secondary pollution. The results show that LIBS technology combined with matrix effect classification regression model was able to realize accurate and quantitative detection of $\mathrm{Cr}$ in biochar, providing a technical reference for the development of related portable or online LIBS detection equipment.

Author Contributions: H.D., G.H. and R.Z. (Rongguang Zhu) designed the experiment; M.G. performed the experiments and data analysis; H.D., R.Z. (Ruoyu Zhang) and L.Z. wrote the whole paper; G.H. acquired the funding; All authors have read and agreed to the published version of the manuscript.

Funding: This work was funded by H2020-WASTE-2014-2015 (690142), National Key Research and Development Project (2018YFD0800100) and National Natural Science Foundation of China (52065055).

Data Availability Statement: Not applicable.

Acknowledgments: We thank the Standards and Quality Inspection Center, Chinese Academy of Agricultural Mechanization Sciences for providing ICP-MS assay.

Conflicts of Interest: The authors declare no conflict of interest.

Sample Availability: Samples of the agricultural biochar are not available from the authors.

\section{References}

1. Zhang, Z.X.; Wu, J.; Chen, W.F. Review on Prepation and Application of Biochar. Adv. Mater. Res. 2014, 898, 456-460. [CrossRef]

2. De Morais, C.P.; Barros, A.I.; Júnior, D.S.; Ribeiro, C.A.; Crespi, M.S.; Senesi, G.S.; Neto, J.A.G.; Ferreira, E.C. Calcium determination in biochar-based fertilizers by laser-induced breakdown spectroscopy using sodium as internal standard. Microchem. J. 2017, 134, 370-373. [CrossRef]

3. Dong, M.; Wei, L.; Lu, J.; Li, W.; Lu, S.; Li, S.; Liu, C.; Yoo, J.H.; Li, W. A comparative model combining carbon atomic and molecular emissions based on partial least squares and support vector regression correction for carbon analysis in coal using LIBS. J. Anal. At. Spectrom. 2019, 34, 480-488. [CrossRef]

4. Sheta, S.; Afgan, M.S.; Hou, Z.; Yao, S.-C.; Zhang, L.; Li, Z.; Wang, Z. Coal analysis by laser-induced breakdown spectroscopy: A tutorial review. J. Anal. At. Spectrom. 2019, 34, 1047-1082. [CrossRef]

5. Andrade, D.F.; Filho, E.R.P. Direct Determination of Contaminants, Major and Minor Nutrients in Solid Fertilizers Using Laser-Induced Breakdown Spectroscopy (Libs). J. Agric. Food Chem. 2016, 64, 7890-7898. [CrossRef]

6. Singh, V.K.; Kumar, V.; Sharma, J. Importance of laser-induced breakdown spectroscopy for hard tissues (bone, teeth) and other calcified tissue materials. Lasers Med Sci. 2014, 30, 1763-1778. [CrossRef] 
7. Jiang, T.; Guo, Z.; Ma, M.; Fang, L.; Yang, M.; Li, S.; Liu, J.; Zhao, N.; Huang, X.; Liu, W. Electrochemical Laser Induced Breakdown Spectroscopy for Enhanced Detection of Cd(II) without Interference in Rice on Layer-by-Layer Assembly of Gra-phene Oxides. Electrochim. Acta 2016, 216, 188-195. [CrossRef]

8. Meng, D.; Zhao, N.; Wang, Y.; Ma, M.; Fang, L.; Gu, Y.; Jia, Y.; Liu, J. On-line/on-site analysis of heavy metals in water and soils by laser induced breakdown spectroscopy. Spectrochim. Acta Part B At. Spectrosc. 2017, 137, 39-45. [CrossRef]

9. Peng, J.; He, Y.; Zhao, Z.; Jiang, J.; Zhou, F.; Liu, F.; Shen, T. Fast visualization of distribution of chromium in rice leaves by re-heating dual-pulse laser-induced breakdown spectroscopy and chemometric methods. Environ. Pollut. 2019, 252, 1125-1132. [CrossRef]

10. Bunn, T.L.; Dietert, R.R.; Ladics, G.S.; Holsapple, M.P.; Bunn, R.R.D.T.L. Developmental Immunotoxicology Assessment in the Rat: Age, Gender, and Strain Comparisons after Exposure to Lead. Toxicol. Methods 2001, 11, 41-58. [CrossRef]

11. Einsporn, S.; Bressling, J.; Koehler, A. Cellular Ellular Localization of Lead Using an Antibody-Based Detection System and Enzyme Activity Changes in the Gills and Digestive Gland of the Blue Mussel Mytilus Edulis. Environ. Toxicol. Chem. 2009, 28, 402-408. [CrossRef]

12. Pearton, S.; Ren, F.; Wang, Y.-L.; Chu, B.H.; Chen, K.H.; Chang, C.Y.; Lim, W.; Lin, J. Recent Advances in Wide Bandgap Semiconductor Biological and Gas Sensors. MRS Proc. 2009, 1202, 1-59. [CrossRef]

13. Douchiche, O.; Driouich, A.; Morvan, C. Spatial Regulation of Cell-Wall Structure in Response to Heavy Metal Stress: Cad-miumInduced Alteration of the Methyl-Esterification Pattern of Homogalacturonans. Ann. Bot. 2010, 105, 481-491. [CrossRef]

14. Huang, E.P.; Marquis, C.P.; Gray, P.P. Development Ofsuper-Cho Protein-Free Medium Based on a Statistical Design. J. Chem. Technol. Biotechnol. 2007, 82, 431-441. [CrossRef]

15. Kramer, K.; Fiedler, M.; Skerra, A.; Hock, B. A Generic Strategy for Subcloning Antibody Variable Regions from the Scfv Phage Display Vector Pcantab 5 E into Pask85 Permits the Economical Production of Fab Fragments and Leads to Improved Recom-binant Immunoglobulin Stability. Biosens. Bioelectron. 2002, 17, 305-313. [CrossRef]

16. Li, H.; Liu, S.; Hassan, M.M.; Ali, S.; Ouyang, Q.; Chen, Q.; Wu, X.; Xu, Z. Rapid Quantitative Analysis of Hg2+ Residue in Dairy Products Using Sers Coupled with Aco-Bp-Adaboost Algorithm. Spectrochim. Acta Part A Mol. Biomol. Spectrosc. 2019, $223,117281$. [CrossRef] [PubMed]

17. Pagliuca, M.G.; Lerose, R.; Cigliano, S.; Leone, A. Regulation by heavy metals and temperature of the human BAG-3 gene, a modulator of Hsp70 activity. FEBS Lett. 2003, 541, 11-15. [CrossRef]

18. Rezk, R.; Galmed, A.; Abdelkreem, M.; Ghany, N.A.; Harith, M. Quantitative analysis of Cu and Co adsorbed on fish bones via laser-induced breakdown spectroscopy. Opt. Laser Technol. 2016, 83, 131-139. [CrossRef]

19. Zhou, X.; Sun, J.; Tian, Y.; Lu, B.; Hang, Y.; Chen, Q. Development of deep learning method for lead content prediction of lettuce leaf using hyperspectral images. Int. J. Remote Sens. 2020, 41, 2263-2276. [CrossRef]

20. Alexander, D.; Ellerby, R.; Hernandez, A.; Wu, F.; Amarasiriwardena, D. Investigation of simultaneous adsorption properties of $\mathrm{Cd}, \mathrm{Cu}, \mathrm{Pb}$ and $\mathrm{Zn}$ by pristine rice husks using ICP-AES and LA-ICP-MS analysis. Microchem. J. 2017, 135, 129-139. [CrossRef]

21. Ayazi, Z.; Banihashemi, M. Determination of trace amount of silver in water samples by flame atomic absorption after preconcentration by ZnO nano sorbent. Sep. Sci. Technol. 2015, 51, 585-593. [CrossRef]

22. Jing, F.; Yang, Z.; Chen, X.; Liu, W.; Guo, B.; Lin, G.; Huang, R.; Liu, W. Potentially hazardous element accumulation in rice tissues and their availability in soil systems after biochar amendments. J. Soils Sediments 2019, 19, 2957-2970. [CrossRef]

23. Ito, S.; Tsukada, K. Matrix Effect and Correction by Standard Addition in Quantitative Liquid Chromatographic-Mass Spectrometric Analysis of Diarrhetic Shellfish Poisoning Toxins. J. Chromatogr. 2001, 943, 39-46. [CrossRef]

24. Choe, K.-Y.; Gajek, R. Determination of trace elements in human urine by ICP-MS using sodium chloride as a matrix-matching component in calibration. Anal. Methods 2016, 8, 6754-6763. [CrossRef]

25. Unsal, Y.E.; Soylak, M.; Tuzen, M. Ultrasound-assisted ionic liquid-based dispersive liquid-liquid microextraction for preconcentration of patent blue $\mathrm{V}$ and its determination in food samples by UV-visible spectrophotometry. Environ. Monit. Assess. 2015, 187, 187-203. [CrossRef] [PubMed]

26. J, S.G.; L, R.M. Hierarchical Clustering Via Joint between-within Distances: Extending Ward's Minimum Variance Method. J. Classif. 2005, 22, 151-183.

27. Du, X. Identifying Control and Management Plane Poison Message Failure by K-Nearest Neighbor Method. J. Netw. Syst. Manag. 2006, 14, 243-259. [CrossRef]

28. Li, Y.; Liu, X.; Zhang, P.; Wang, X.; Cao, Y.; Han, L. Qualitative and quantitative correlation of physicochemical characteristics and lead sorption behaviors of crop residue-derived chars. Bioresour. Technol. 2018, 270, 545-553. [CrossRef]

29. Medyńska-Juraszek, A.; Ćwielag-Piasecka, I.; Jerzykiewicz, M.; Trynda, J. Wheat Straw Biochar as a Specific Sorbent of Cobalt in Soil. Materials 2020, 13, 2462. [CrossRef]

30. Tang, Y.; Li, J.; Hao, Z.; Tang, S.; Zhu, Z.; Guo, L.; Li, X.; Zeng, X.; Duan, J.; Lu, Y. Multielemental self-absorption reduction in laser-induced breakdown spectroscopy by using microwave-assisted excitation. Opt. Express 2018, 26, 12121-12130. [CrossRef]

31. Fu, X.; Duan, F.-J.; Huang, T.-T.; Ma, L.; Jiang, J.-J.; Li, Y.-C. A fast variable selection method for quantitative analysis of soils using laser-induced breakdown spectroscopy. J. Anal. At. Spectrom. 2017, 32, 1166-1176. [CrossRef]

32. Duan, F.; Fu, X.; Jiang, J.; Huang, T.; Ma, L.; Zhang, C. Automatic variable selection method and a comparison for quantitative analysis in laser-induced breakdown spectroscopy. Spectrochim. Acta Part B At. Spectrosc. 2018, 143, 12-17. [CrossRef] 
33. Wang, T.; He, M.; Shen, T.; Liu, F.; He, Y.; Liu, X.; Qiu, Z. Multi-Element Analysis of Heavy Metal Content in Soils Using La-serInduced Breakdown Spectroscopy: A Case Study in Eastern China. Spectrochim. Acta Part B At. Spectrosc. 2018, 149, 300-312. [CrossRef]

34. Duan, H.; Han, L.; Huang, G. Quantitative Analysis of Major Metals in Agricultural Biochar Using Laser-Induced Breakdown Spectroscopy with an Adaboost Artificial Neural Network Algorithm. Molecules 2019, 24, 3753. [CrossRef] [PubMed]

35. Xu, X.; Li, A.; Wang, X.; Ding, C.; Qiu, S.; He, Y.; Lu, T.; He, F.; Zou, B.; Liu, R. The high-accuracy prediction of carbon content in semi-coke by laser-induced breakdown spectroscopy. J. Anal. At. Spectrom. 2020, 35, 984-992. [CrossRef]

36. Song, J.; Zhang, S.; Li, G.; Du, Q.; Yang, F. Preparation of montmorillonite modified biochar with various temperatures and their mechanism for $\mathrm{Zn}$ ion removal. J. Hazard. Mater. 2020, 391, 121692. [CrossRef]

37. Duan, H.; Ma, S.; Han, L.; Huang, G. A novel denoising method for laser-induced breakdown spectroscopy: Improved wavelet dual threshold function method and its application to quantitative modeling of $\mathrm{Cu}$ and $\mathrm{Zn}$ in Chinese animal manure composts. Microchem. J. 2017, 134, 262-269. [CrossRef]

38. Taylor, P.J. Matrix effects: The Achilles heel of quantitative high-performance liquid chromatography-electrospray-tandem mass spectrometry. Clin. Biochem. 2005, 38, 328-334. [CrossRef]

39. Van Eeckhaut, A.; Lanckmans, K.; Sarre, S.; Smolders, I.; Michotte, Y. Validation of bioanalytical LC-MS/MS assays: Evaluation of matrix effects. J. Chromatogr. B 2009, 877, 2198-2207. [CrossRef]

40. Xue, J.; Yang, Z.; Han, L.; Liu, Y.; Liu, Y.; Zhou, C. On-line measurement of proximates and lignocellulose components of corn stover using NIRS. Appl. Energy 2015, 137, 18-25. [CrossRef] 